\title{
A Review of Boiler Operational Risks in Empty Fruit Bunch Fired Biopower Plant
}

\author{
Fares A. Alaw and Nurul S. Sulaiman* \\ Faculty of Chemical and Process Engineering Technology, Universiti Malaysia Pahang, Lebuhraya Tun Razak, 26600 Gambang, Pahang, \\ Malaysia.
}

\begin{abstract}
Growing popularity of biomass power generation process is connected to its label of green and cheap renewable energy. As the second-largest producer of crude palm oil, Malaysia has abundance of biomass residues from palm oil industries and other renewable organic matters which can be converted to bio-chemicals to generate electricity. However, despite institutional arrangements, policy frameworks, funding mechanisms and incentives to support the growth of the biomass industry, there are several risks which may prone to reduce efficiency of biopower boiler especially empty fruit bunch as the fuels that cannot be ignored. Boiler is one of the primary equipment of power generation plants, in a significant role in converting biofuel to electricity. With increasing numbers of potentials of biomass as raw materials for renewable energy uses, new risks may be found. Yet there has been very little research into these risks and how to prevent them. Lack of understanding of modern risk identification methods, such as HAZOP, with the biopower industry is one of the reasons for the industry's slow growth. An industry evolves through life cycle stages and at each stage presents risk factors such as overheating, oxygen corrosion and clinker. This paper identifies several key risks associated with EFB fired biopower boiler in Malaysia. The overview of risks not only provide a perspective from which an industry's viability can be evaluated but also help the operators to better understand key risks and improve boiler capacity as well as plan their risk mitigation strategies more effectively.
\end{abstract}

\section{KEYWORDS}

Biopower Boiler, Risk Analysis, Biopower plant, Risk factors.

\section{INTRODUCTION}

Renewable energy is one of the major contributors in fulfilling the world's energy demand. Biomass is one in all the renewable energy sources that are presently being exploited by the biomass industries. Malaysia produces a minimum of 168 million tonnes of biomass, as well as timber and palm waste, rice husks, coconut trunk fibers, municipal waste and sugar cane waste annually (Hamzah et al., 2019). The biomass industries started using biomass wastes as fuel for energy sources due to the low rates of pollution and they can cut back the number of waste drop. Palm oil industries use the waste from processed palm fruits, namely mesocarp fibre, kernel shell and empty fruit bunch as fuel to get steam so as to burn the fuel and generate power (Müllerová, 2013).

In Malaysia, with the launch of the 1Malaysia Biomass Alternative Strategy (1MBAS) on 22nd March 2012, by previous Prime Minister Datuk Seri Najib Tun Razak, that strengthen execution of the national biomass strategy and expand the strategy to different sources of the Malaysian biomass. The initiative aims to encourage additional native and foreign firms to establish partnerships within the biopower trade and accelerate the industry's growth. 1MBAS would concentrate on driving new clean sources of power generation, minimize the utilization of fossil fuels in power generation, driving inclusiveness through job creation and enhance development of power generation industries through utilization of biomass. This can establish a brand new supply of leading edge, high-value industries and additional accomplished jobs for Malaysians quickly increase the wealth of this country by exploiting the biopower processes (IRENA, 2018).

Malaysia has a target to install RE (Renewable Energy) capacity of $2080 \mathrm{MW}, 11 \%$ of RE in its energy generation mix and 42.2 million tons of cumulative $\mathrm{CO}_{2}$ avoidance by this year of 2020. By year 2030, the renewable capacity target is expected to reach $4000 \mathrm{MW}, 17 \%$ of RE generation mix and 145.1 million tons of cumulative $\mathrm{CO}_{2}$ avoidance excluding large scale hydropower schemes. The Malaysia's national biomass target is to achieve $800 \mathrm{MW}(38 \%)$ and $54 \mathrm{MW}(17 \%)$ installed capacity from biomass and solid waste respectively, by this year of 2020 as shown in Figure 1. By year 2030, the biomass installed capacity is expected to increase to $67.5 \%$ and $1340 \mathrm{MW}$ installed capacity (AIMNBS, 2020). 


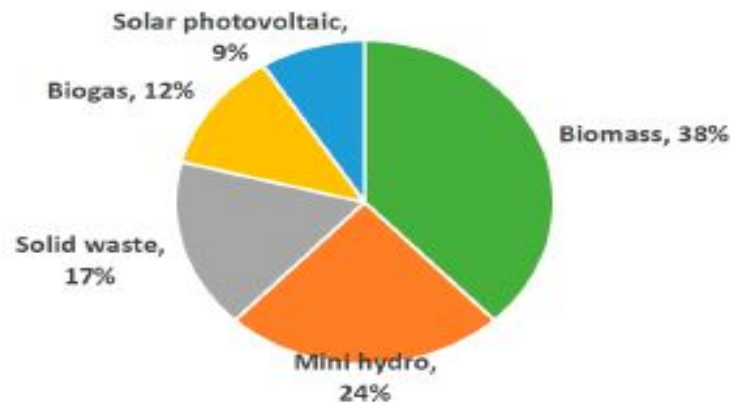

Figure 1. 2080 MW renewable energy (RE) installed capacity target by 2020 (AIMNBS, 2019).

Malaysia has approximately 4 million hectares of land under oil palm plantation. Over $75 \%$ of total area planted is located in just three states, Sabah, Pahang and Sarawak, each of which has over half a million hectares under cultivation. Empty fruit bunch (EFB) is one of the most produced biomass in Malaysia, about 20.6 million tons annually. In 2015, there were several biopower companies utilizing EFB that the biomass industry had planned to install, but only few companies are available now due to the cost and safety processing EFB for power generation. Companies such as FTJ Biopower Sdn Bhd, Kina Biopower Sdn.Bhd. and Seguntor Bioenergy Sdn.Bhd managed to convert EFB to fuel for electricity generation (Aghamohammadi et al., 2017). There are many potential risks from using EFB as fuel for power generation. This paper aims to provide a comprehensive review focusing on the risk factors that affecting the boiler for using EFB as fuel for power generation.

\section{BIOPOWER PRINCIPLE}

Biomass is a renewable energy source not only because the energy comes from the sun, but also because biomass can re-grow over a relatively short period of time compared with fossil fuels. Through the process of photosynthesis, chlorophyll in plants captures the sun's energy by converting carbon dioxide from the air and water from the ground into carbohydrates. When these carbohydrates are burned, they turn back into carbon dioxide and water and release the energy they captured from the sun, this is the main consideration for biopwer plant when installed (Hamzah et al., 2019).

Biopower plants usually using direct combustion power generation. The process of direct burning or combustion is biofuel entering the furnace or boiler in a variety of ways: can be packaged straw, crushing granulation (block), or powder, or mixed with coal. The production process (Figure 2) is started by the fuel entering the boiler combustion area. During the heating process, the water is converted to superheated steam. After the steam generated, high pressure steam flowing towards the turbine. The rotating turbine generator is driven by the high pressure steam, the steam internal energy is transformed into mechanical energy, and finally the mechanical energy is converted into electrical energy by the generator (Roy \& Dias, 2017).

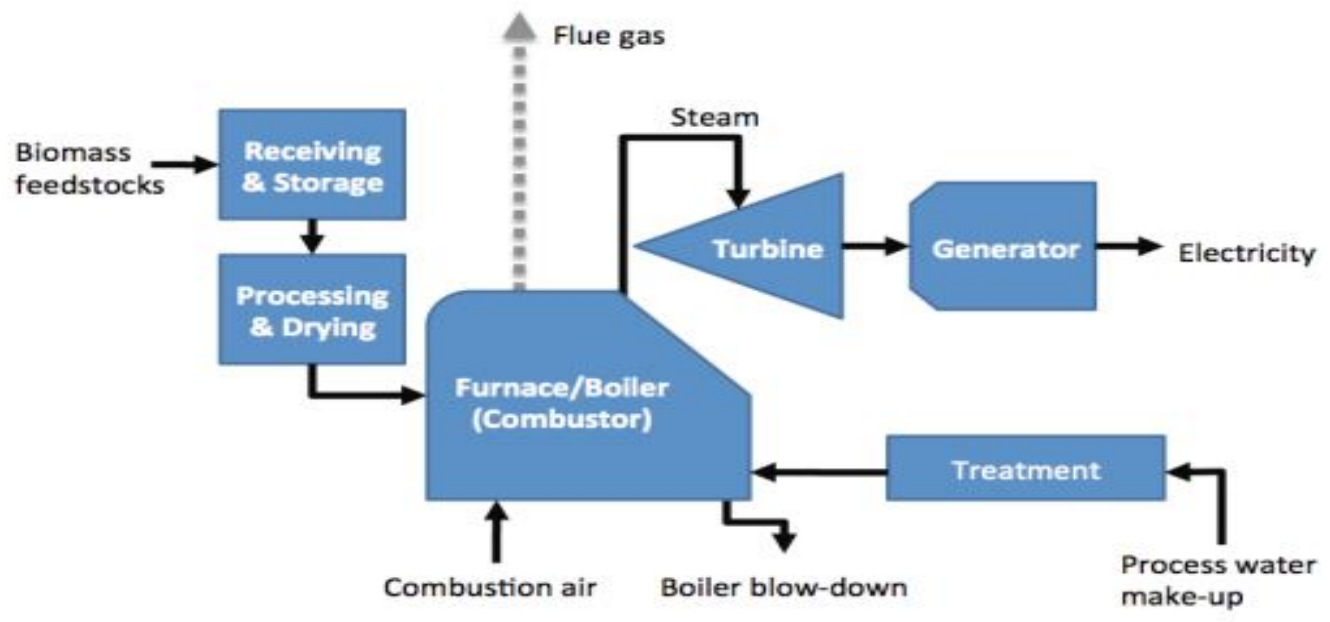

Figure 2. Biopower process flow diagram (Roy \& Dias, 2017).

\section{BIOPOWER PLANT BOILER}

Generally, thermal biopower power generation system consists of boiler, turbine, fuel pretreatment and water treatment system. The foremost necessary elements of a steam powerhouse system is the boiler. Boilers could be a section that is acquainted with convert water into steam through a warming strategy. Steam is then used to drive a rotary engine and a generator coupled to get electrical power. Boilers are pressure vessels used for heating water or manufacturing steam to supply heating facility in industries and to get electricity through driving steam turbines (Ali \& Erna, 2014). 
Boilers are usually used as steam generation systems in several industries for the heating processes. Thermal biopower plants use boilers to get steam for steam turbines. A major portion of Malaysia energy consumption is found to be used for operative boilers to facilitate the heating method or power generation. However, boiler potency is within $75-90 \%$ and also the remaining part of the energy is lost as totally different types of wasted heat. The potential risks of the heating power of the boiler is sustained by taking measures to regulate the process offering additional info and suppleness to the biopower trade for higher risk management. The thermochemical safety for agriculture residues in heating process is more challenging than wood as the ash content in wood is usually less than many agricultural residues. This is due to challenges in securing adequate feedstock for the long-term supply for biomass, difficulties in securing financing for biopower technologies and lack of experts in the technology project developers, financial personnel and safety management (Basu \& Kefa, 2014).

\section{TYPES OF BOILER}

There are two main boilers used in power generation which are fire-tube boiler and water-tube boiler.

\section{Fire-tube boiler}

In a fire-tube boiler, combustion gases pass through tubes with water surrounding the outside of the tubes. The advantages of a fire-tube boiler are its simple construction and less rigid water treatment requirements. The disadvantages are the excessive weight-per-pound of steam generated, excessive time required to raise steam pressure because of the relatively large volume of water, and inability to respond quickly to load changes, again, due to the large water volume (Salman Zafar, 2019).

\section{Water-tube boiler}

In a water-tube boiler, the water is inside the tubes and combustion gases pass around the outside of the tubes. The advantages of a water-tube boiler are a lower unit weight-per-pound of steam generated, less time required to raise steam pressure, a greater flexibility for responding to load changes, and a greater ability to operate at high rates of steam generation. This type of boiler is mostly used by biopower plants due to ability to handle higher pressures up to 5,000 psig and faster recovery time than fire-tube boiler (Salman Zafar, 2019).

\section{Properties of EFB as boiler feed}

Empty fruit bunches (EFB) is becoming a popular source of fuel for renewable energy (RE) power generation. EFB fibers are resulting from the palm-oil extraction and milling process. In its raw state, EFB is both very fibrous and wet, typically at approximately $67 \%$ moisture content. If it could be dried, it would be an excellent fuel for power boilers. For thermochemical process efficiency, it is significant to have the lowest possible moisture content of biomass since high moisture content of biomass will incur in drying cost. The fuel composition is important with respect to calorific value (amount of calories generated when a unit amount of substance is completely oxidized) during combustion. The calorific value of EFB varies between 18 to $21 \mathrm{MJ} / \mathrm{kg}$ on a dry basis (Ruksathamcharoen et al., 2019).

In addition, the presence of alkali and alkaline earth metal content of oil palm biomass such as sodium (Na), magnesium $(\mathrm{Mg})$, calcium $(\mathrm{Ca})$ and potassium $(\mathrm{K})$ is very important in thermochemical combustion as it may react with silica ( $\mathrm{Si}$ ) causing operational problems in the boiler with slagging in the grates and fouling of the tubes. EFB has the highest alkali index correspond to high $\mathrm{K}$ with potential of slagging during combustion. Therefore, it is important to reduce these elements by leaching or washing with water to avoid fouling or slagging during combustion (Salman Zafar, 2019).

\section{BOILER RISK FACTORS}

Figure 3 shows the structure of the boiler process for biopower plant. Boiler systems are comprised of the major components described below:

1) Fuel Heater: many boilers firing heavy fuel oil require fuel heaters to reduce the fuel viscosity.

2) Deaerator: is a feedwater heater that is designed to promote the removal of non-condensable gases from the boiler feedwater. The principal gases of concern are oxygen, carbon dioxide, and ammonia

3) Economizer: is an energy recovery device that uses the hot exhaust gases from the boiler (waste heat) to heat combustion air or feedwater.

4) Combustion Air Blowers: In many packaged boiler installations, the combustion air fan is designed and provided by the boiler manufacturer and is integral with the boiler housing.

5) Steam traps: Steam traps are installed throughout steam systems to remove condensate (spent steam), air, and non-condensable gases from the steam system.

6) Condenser: is used to condense steam with low pressure for reprocessing.

Boiler hazards exist in the following functional areas: 


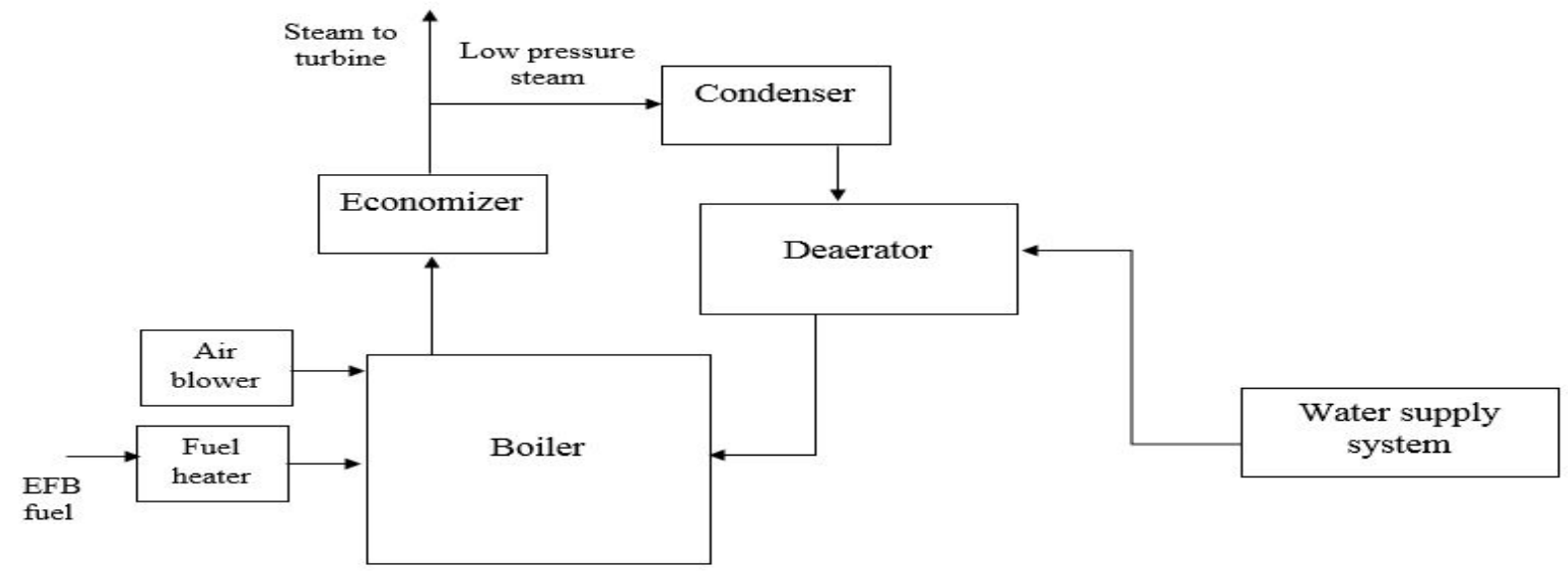

Figure 3. Boiler main areas (Noriyati et al., 2014).

\section{BIOFUEL PRETREATMENT}

Facilities using EFB as the primary supply will offer a reliable source for base load. However, evaluation of environmental and occupational health impacts needs an understanding of the properties and characteristics of the fuel, moreover as thought of fuel process, handling and storage. Pre-treatment steps such as shredding/chipping and dewatering (screw pressing or drying) are necessary in order to improve the fuel property of EFB (Yatim et al., 2017). The risks that are important to be consider for fuel preparation are:

\section{Clinker}

A softened/melted ash (Figure 4) due to the empty fruit bunch freezing point and its high metal content resulted in formation of silicon oxide. Clinkering happens in a boiler combustion chamber when ash melts and fuses into a hard, glassy slag. Ashes may deposited at combustion facet wall, chamber floor, chamber ceiling. This can cause a blockage at the pipes of the boiler which could possible lead to overheating (Nzotcha \& Kenfack, 2018).

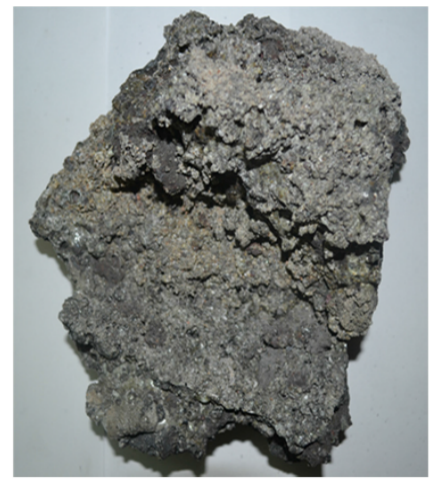

Figure 4. Clinker (Nzotcha \& Kenfack, 2018).

\section{Moisture content}

The moisture content testing is consider a critical step regarding the use of biomass. High level of moisture can cause less burning which is a major problem for biopower plant boiler. The condition for the boiler to burn the fuel properly is the moisture content of the fuel lesser than $40 \%$. When utilizing EFB as fuel, the high moisture content of EFB affects strongly the combustion process such as lowering the flame temperature and/or the boiler efficiency Unprocessed EFB is presented as very wet whole empty fruit bunches each weighing several kilograms while treated EFB is a fibrous material with fiber length of 10-20 cm and reduced moisture content of 30-50\%. Additional processing steps can reduce fiber length to around $5 \mathrm{~cm}$ and the material can also be processed into bales, pellets or pulverized form after drying (Deborah \& Carlos, 2016).

\section{Moveable parts}

Examination engineers should make sure the boiler and pellet feed mechanism is cleansed and maintained by a competent person as given by the manufacturers' directions. Inappropriate maintenance regime resulting in worn parts, attainable blockages among the system that has the potential to cause a sludge concentration which could lead on to an explosion and a buildup of carbon deposits/soot in ash (William Reeves, 2014). 


\section{DEAERATOR}

Boiler deaerators commonly used to remove oxygen and different gases from the water that feeds into boilers that generate steam. Deaerators are helpful as they take away the gases that attach to the metallic parts of the steam system which may cause corrosion by forming oxides, or rust (Hill et al., 2014). The risks that effect the process are:

\section{Bubbles build-up}

Bubbles or froth build up on the surface of the boiler water and pass out with steam is termed as foaming. In theory suspended solids collect in the surface film surrounding a steam bubble and make it tougher. The steam bubble therefore resists breaking and builds up foam which it will cause blockage in pipes. It is believed that the finer the suspended particles the greater their collection in the bubble. Causes by high total dissolved solids (TDS) that comprise inorganic salts (principally calcium, magnesium, potassium, sodium, bicarbonates, chlorides, and sulfates) and some small amounts of organic matter that are dissolved in water (Ruksathamcharoen et al., 2019).

\section{Oxygen corrosion}

Additionally referred to as corroding in boiler drum, low oxygen ion concentration cause acid attack on the metal surface within the boiler system. Oxygen is extremely corrosive in presence of hot water. Dissolved oxygen in feed water will become terribly aggressive once heated and reacts with the boiler's internal surface to create corrosion of parts on the metal surface (Umar et al., 2014).

\section{Overheating}

Hazards from the wet facet are terribly the same as gas or oil boilers. Specifically systems for higher temperatures and steam boilers, may have to adjust to the Pressure Equipment Regulations 1999 (PER) and Pressure Systems Safety Regulations 2000 (PSSR) [17]. In practice, several biomass boiler will contain oil or gas boilers operating aboard the biomass system. Therefore, construction of the complete power generation site in accordance with these laws ought to manufacture an installation that's fit purpose. The foremost necessary purpose that distinguishes biomass from oil or gas is that the use of biomass fuel, EFB, is really risky. It takes so much effort to extinguish burning EFB fibers inside the furnace. Biomass boilers have giant thermal inertia caused by fuel burning on the grate and doubtless additionally residual heat keep within the refractory. Managing boiler heating process with biomass fuel should be very careful, particularly once coping with steam systems wherever loss of power or loss of feed facility might lead a way bigger hazard that cannot be maintained (Saidur \& Masjuki, 2014).

\section{ECONOMIZER}

Steam that comes from biopower boilers are generally at a temperature range of $200-400^{\circ} \mathrm{C}$. Stack economizers recover a portion of this heat for pre-heating the feed water and/or combustion air. The water is most frequently used for boiler make-up water or another would like that coincides with boiler operation. The savings potential relies on the prevailing stack temperature, the quantity of make-up water required, and also the hours of operation (Bauer et al., 2013). The risk which will occur is:

\section{Presence of magnetic iron oxide}

Magnetic compound deposits at the purpose of failure are an immediate indication of reaction of the tube metal. This reaction happens throughout warming wherever metal temperatures exceed the planning temperature and also the steel enters into an immediate reaction with the steam to create magnetic iron compound with element unharness. Once the deposits found within the space of failure are primarily iron compound, it should be necessary to explore variety of operative conditions so as to work out the initial cause (Bauer et al., 2013).

\section{Feed water erosion}

High-velocity water and especially water/steam mixtures cause erosion in feed water systems. The most commonly encountered erosion problems occur at the hairpin bends in steaming economizers. Here, the mixture of steam and water thins the elbows, leaving a characteristic reverse horseshoe imprint. Similar problems can be encountered in feed water lines where high velocities create the familiar thinning pattern. These problems can occur even at moderate average flow velocities when a sequence of bends causes a significant increase in local velocity (Wing \& Jin, 2015).

\section{WATER COOLING SYSTEM}

Water cooling system such as cooling towers are a heat rejection system that rejects waste heat to the atmosphere through the cooling of a water stream to a lower temperature. Cooling towers may either use the evaporation of water to remove process heat and cool the working fluid to near the wet-bulb air temperature or, in the case of closed circuit dry cooling towers, rely solely on air to cool the working fluid to near the dry-bulb air temperature (Duncan \& Glyn, 2019). The main risks of cooling tower system are: 


\section{Stagnant water}

Stagnant water is basically a lack of water circulation, which it will likely result in solids in the system settling out as sludge. This may encourage the formation of biofilm. Lack of circulation will also almost certainly mean that any biocides or other chemicals being added will not reach all parts of the system. Cooling tower must be well-maintain the speed of circulation, any blockage in pipes could lead to corrosion or rupture (Kimberley Coke, 2016).

\section{Dead legs}

Dead legs in a cooling tower system are pipes that are full of water, but have little or no flow through them. A potential dead leg is any pipe that branches off from another main pipe and has a length longer than the internal diameter of the main pipe. Other components of a cooling tower system, such as off-line chillers or stand-by pumps, may also potentially become dead legs (Criscuolo \& Menon, 2015).

\section{CAUSE EFFECT RELATIONSHIPS}

Once the risks have been identified, the relationships among the factors were expressed into a directed acyclic graph (DAG) as in Figure 5. The graphical representation, Bayesian Network (BN), indicating the relevant variables (nodes) and dependencies (arcs) were established. Bayesian Network is an inexorably famous technique for demonstrating unsure and complex systems, for example, biological communities and ecological administration (Weber et al., 2014).

Referring to the data gathered, the main risks areas are categorized into fuel preparation, water cooling system, deaerator, and economizer as depicted in Figure 5. To understand the cause of the factors, network/graph may best represent the relationship between cause and effect emphasized on the mechanism of boiler efficiency/working principle. Thus, this framework may help to the decision maker to identify the underlying factors of the biopower boiler efficiency.

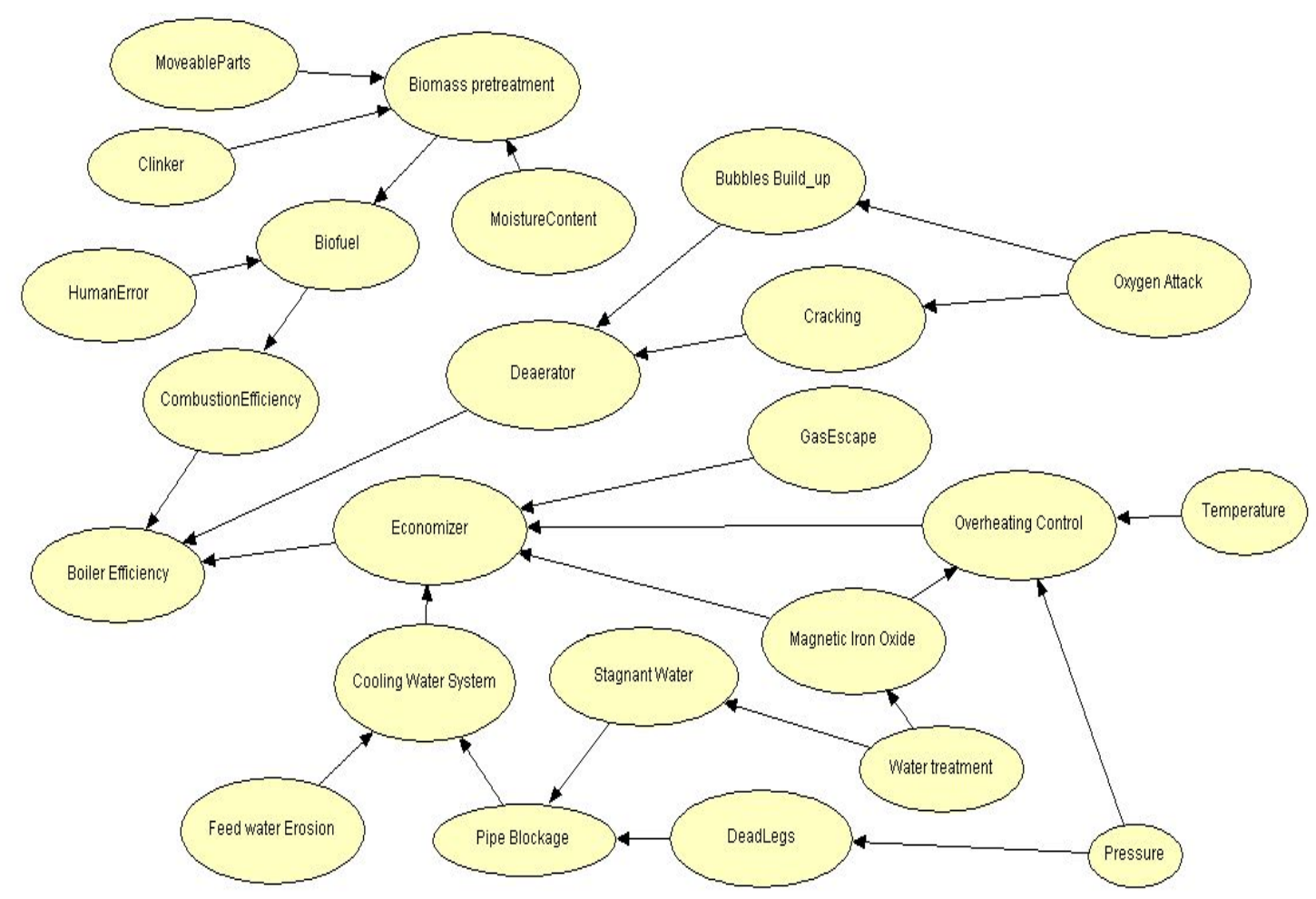

Figure 5. Bayesian Network model for biomass boiler

\section{CONCLUSION}

In conclusion, Malaysia has wealth of biomass buildups from palm oil plants and other inexhaustible natural organics which can be changed over to bio-power. The high availability of EFB as the feedstock for energy production endorse the concept of waste-to wealth. EFB offers significant advantages as a combustion feedstock due to the high volatility and reactivity of the fuel. While there are many attractive reasons to consume EFB in biopower plant, EFB as fuel has also potential risks in biopower plant boiler. Biomass power plant boiler is one of the primary equipment of fired fuel power plants. The importance of the knowledge of biopower boiler risks plays a crucial role because the boiler depends on accurate parameters. If the boiler failed, it will lead to a catastrophic accident and loss of lives. The modern graphical representation, Bayesian network, is being used as a solution in establishing effective error management and provide information about the essential factors that need to be controlled. Thus, this framework may support discussing on the factors that may become one of the biggest risk for biopower plant boiler. 


\section{ACKNOWLEDGMENT}

The author gratitude goes to the Research and Innovation Department, Universiti Malaysia Pahang, Malaysia, for their financial support through the Master Research Scholarships (MRS).

\section{REFERENCES}

Agensi Inovasi Malaysia National Biomass Strategy (AIMNBS). (2019). New Wealth Creation for Malaysia's Palm Oil Industry; Agensi Inovasi Malaysia: Cyberjaya, Malaysia.

Aghamohammadi, N.; Reginald, S.; Shamiri, A.; Zinatizadeh, A.; Wong, L.; Nik Sulaiman, N. (2017). An Investigation of Sustainable Power Generation from Oil Palm Biomass: A Case Study in Sarawak.

Ali, M., Erna, Z. (2014). Risk Management and Hazard and Operability Study on Steam Turbine Power Plant Unit-5 in the Power Generation Paiton, East Java-Indonesia. Adv. in Nat. Appl. Section 7(5): 510 -516.

Basu, P., Kefa, C. (2014). Boilers and burners: design and theory. Springer Science \& Business Media. Salman Zafar, October 7 , 2019. Energy Potential of Empty Fruit Bunches. (BioEnergy Consult Powering Clean Energy Future).

Bauer, R., et al., (2013) Modelling of Grate Combustion in a Medium Scale Biomass Furnace for Control Purposes. Biomass and Bioenergy. 34(4): p. 417-427.

Criscuolo, C., Menon, C. (2015). Environmental policies and risk finance in the green sector: cross-country evidence. Energy Policy $83: 38-56$

Deborah, L., Carlos, S. (2016). Handbook of Industrial Water Treatment (Chapter 14 - Boiler System Failures). Available online: (https://www.suezwatertechnologies.com/handbook/chapter-14-boiler-system-failures)

Duncan, M., and Glyn, D. (2019). Cooling Towers: Controlling The Critical Risks and Operational Programs. University of Melbourne. Available online: (https://safety.unimelb.edu.au/_data/assets/pdf_file/0005/1835942/cooling-tower-controlling-the-criticalrisks-and-operational-programs.pdf)

Hamzah, N., Tokimatsu, K., \& Yoshikawa, K. (2019). Solid Fuel from Oil Palm Biomass Residues and Municipal Solid Waste by Hydrothermal Treatment for Electrical Power Generation in Malaysia : A Review.

Hill, B. R. T., Fimeche, B. C., Limited, A. D. L., \& Cb, C. (2014). Pipelines risk analysis. IChemE, 657-670.

International Renewable Energy Agency (IRENA). (2018). Available online: (http://www.irena.org/publications/2018/Oct/Renewable-Energy-in-Cities).

Kimberley Coke. (2016). Cooling Tower Maintenance Program and Plan. New York City Department of Education. (https://www.optosfns.org/nycdsf/referenceDoc/programs/safety/Cooling_Tower_Water_Management_Plan_Final_KC.pdf)

Müllerová, J. (2013). Fire Safety Properties of Heat Treated Wood. Research Journal of Recent Sciences, India, vol. 2/issue12), pp 8082.

Noriyati, R.,D., Pradana, S.,H., Dacosta, S.,R., Musyafa, A. \& Suprijanyo, A. (2014) "Risk Assessment and Safety Analysis on Power Generation Boiler At PT.Petrokimia Gresik,Indonesia" International Journal of Science and Technology (IJSTE), Vol. 1 No. 3, September 2012,1-10.

Nzotcha, U.; Kenfack, J. (2018). Contribution of the wood-processing industry for sustainable power generation: Viability of biomassfuelled cogeneration in sub-Saharan Africa.

Roy, P.; Dias, G. (2017). Prospects for pyrolysis technologies in the bioenergy sector: A review. Renew. Sustain. Energy Rev. 2017, $77,59-69$.

Ruksathamcharoen, S.; Ajiwibowo, M.W.; Chuenyam, T.; Surjosatyo, A.; Yoshikawa, K. (2018). Effect of Hydrothermal Treatment on Grindability and Fuel Characteristics of Empty Fruit Bunch Derived Hydrochar. Int. J. Technol. 9, 1246.

Salman Zafar, October 7, 2019. Bioenergy Developments in Malaysia. (BioEnergy Consult Powering Clean Energy Future).

Saidur, R., and Masjuki, H. (2014). Energy, Exergy and Economic Analysis of Industrial Boilers. Energy Policy;38(5):2188-97.

Umar MS, Jennings P, Urmee T (2014) Sustainable electricity generation from oil palm biomass wastes in Malaysia: an industry survey. Energy 67:496-505.

William L. Reeves. (2014). Maintaining Boiler Safety by a Good Water Circulation System. Engineering Applications of Artificial Intelligence, 71-82.

Wing LC, Jin Z (2015) Risk management methods applied to renewable and sustainable energy: a review. J Electr Electron Eng 3(11):1-12.

Weber, P., Medina-Oliva, G., Simon, C., \& Iung, B. (2014). Overview on Bayesian networks applications for dependability, risk analysis.pdf.

Yatim, P., Lin, N.S., Lam, H.L. et al. (2017). Overview of the key risks in the pioneering stage of the Malaysian biomass industry. Clean Techn Environ Policy 19, 1825-1839 doi:10.1007/s10098-017-1369-2. 